\title{
Movements and habitat use of satellite-tagged whale sharks off western Madagascar
}

\author{
Stella Diamant ${ }^{1,2,3}$, Christoph A. Rohner ${ }^{2}$, Jeremy J. Kiszka ${ }^{1,4}$, \\ Arthur Guillemain d'Echon ${ }^{1,3}$, Tanguy Guillemain d'Echon ${ }^{1,3}$, Elina Sourisseau ${ }^{1,3}$, \\ Simon J. Pierce ${ }^{1,2, *}$ \\ ${ }^{1}$ Madagascar Whale Shark Project, Nosy Be, Madagascar \\ ${ }^{2}$ Marine Megafauna Foundation, Donner Pass Rd., Truckee, CA 96161, USA \\ ${ }^{3}$ Mada Megafauna, Nosy Be, Madagascar \\ ${ }^{4}$ Department of Biological Sciences, Florida International University, North Miami, FL 33181, USA
}

\begin{abstract}
Whale sharks Rhincodon typus, the world's largest fish, are routinely sighted off the northwest coast of Madagascar, particularly off the island of Nosy Be. Dedicated whale shark tourism has been developing in the area since 2011. During our first dedicated survey, from September to December 2016, we photo-identified 85 individual whale sharks ranging from 3.5 to $8 \mathrm{~m}$ in total length (all juveniles). None had been previously identified from surrounding countries. We tagged 8 sharks with tethered SPOT5 tags in October 2016, with tracking durations of 9 to $199 \mathrm{~d}$. Kernel density plots showed that the main activity hotspot for tagged sharks was around the Nosy Be area. Three individuals were resighted back at Nosy Be in late 2017 after having lost their tags. A secondary hotspot was identified off Pointe d'Analalava, $180 \mathrm{~km}$ southeast of Nosy Be. Five sharks swam off the shelf into the northeastern Mozambique Channel, between Madagascar and Mayotte, and one of these continued to near the Comoros islands. Two sharks swam to southern Madagascar, with minimum track distances of 3414 and $4275 \mathrm{~km}$. The species is presently unprotected in Madagascar, although a small proportion of the high-use area we identified in this study is encompassed within 2 marine protected areas adjacent to Nosy Be. Whale sharks are globally endangered and valuable to the local economy, so there is a clear rationale to identify and mitigate impacts on the sharks within the 2 hotspots identified here.
\end{abstract}

KEY WORDS: Satellite tagging $\cdot$ Population ecology $\cdot$ Conservation biology $\cdot$ Kernel density analysis · Marine megafauna

\section{INTRODUCTION}

Whale sharks Rhincodon typus, the world's largest fish, aggregate seasonally in certain areas within their circumtropical distribution (Rowat \& Brooks 2012). The western Indian Ocean (WIO) hosts several coastal whale shark feeding areas, with high densities of sightings documented around Praia do Tofo in Mozambique (Cliff et al. 2007, Pierce et al. 2010, Rohner et al. 2013, 2015a), Mahé in the Seychelles (Rowat et al. 2009, 2011) and Mafia in Tanzania (Rohner et al. 2015a). Whale sharks are also widely

\footnotetext{
*Corresponding author: simon@marinemegafauna.org
}

distributed in the oceanic waters of the WIO, particularly within the Mozambique Channel (Sequeira et al. 2012). Their presence in the coastal areas is typically related to high prey abundance (Rohner et al. 2015b, 2018), while in offshore waters their movements are likely correlated with productive frontal zones (Ramírez-Macías et al. 2017, Ryan et al. 2017).

Limited data are available on whale shark movements within the WIO, although genetic data support a single subpopulation within the Indo-Pacific (Castro et al. 2007, Schmidt et al. 2009, Vignaud et al. 2014). However, international photo-identification

๑ The authors 2018. Open Access under Creative Commons by Attribution Licence. Use, distribution and reproduction are unrestricted. Authors and original publication must be credited. 
comparisons have shown limited connectivity between the known feeding areas in the region, which include Djibouti, the Maldives, Mozambique, the Seychelles, South Africa and Tanzania (Brooks et al. 2010, Andrzejaczek et al. 2016, Norman et al. 2017) along with the Arabian Gulf and Gulf of Oman (Robinson et al. 2016). The few published satellite tracks from the WIO have not shown significant interchange between these feeding areas (Gifford et al. 2007, Rowat et al. 2007, 2009, Brunnschweiler et al. 2009, Rohner et al. 2018). However, interpretation of these results is complicated by the biased population structure at these sites, with all the aforementioned feeding areas dominated by male sharks, typically juveniles (Rohner et al. 2015a, Norman et al. 2017).

The predictable aggregative behavior of whale sharks leaves them particularly vulnerable to human impacts. The species was uplisted to globally Endangered on the IUCN Red List of Threatened Species in 2016 because of overfishing, bycatch and ship strikes (Pierce \& Norman 2016). The species remains unprotected in several WIO nations, although the 2017 listing of the whale shark in Appendix I of the Convention on Migratory Species (CMS) means signatory nations are now required to prohibit take. Significant declines in sightings have been noted in long-term hotspots in Mozambique (Rohner et al. 2013) and the Seychelles (D. Rowat pers. comm.) as well as broadly within the northern Mozambique Channel (Sequeira et al. 2012). Further data are required to determine whether these local declines in whale shark sightings represent a spatial shift in distribution or a genuine population-level decrease in abundance.

The distribution, status and abundance of whale sharks are poorly documented in Madagascar (Jonahson \& Harding 2007, Kiszka \& van der Elst 2015). Jonahson \& Harding (2007) conducted an interviewbased survey of whale sharks in Madagascarknown locally in the Sakalava dialect as marokintana, meaning many stars - and identified the island of Nosy Be in the northwest as the area with the most consistent sightings. Follow-up fieldwork by the Wildlife Conservation Society in 2005 and 2006 identified 15 individual whale sharks off Nosy Be, with a mean total length (TL) of $6.1 \mathrm{~m}$ (R. Graham pers. comm.). Dedicated whale shark tourism started in 2011, although dive operators had been searching for whale sharks opportunistically prior to 2007 (Jonahson \& Harding 2007). There are presently no regulations specifically pertaining to whale shark tourism, but best-practice voluntary guidelines were implemented by most operators over the 2016 and 2017 season. Operators perceive sightings off Nosy Be to be increasing to the present, although it is unclear whether these sightings may be correlated to a rising search effort as tourism increases. Whale sharks are wide ranging, and local existing marine protected areas (MPAs) in northwestern Madagascar, including the community-managed Ankivonjy $\left(1394 \mathrm{~km}^{2}\right.$, located $50 \mathrm{~km}$ southeast of Nosy Be) and Ankarea $\left(1356 \mathrm{~km}^{2}, 50 \mathrm{~km}\right.$ northeast of Nosy Be), are unlikely to offer adequate protection for this species. To generate management measures for whale sharks in Madagascar and in the WIO, information on their movements and population structure is needed.

Here we used tethered satellite tags to provide the first data on the spatial habitat use of whale sharks in the Nosy Be area and more broadly within the southwestern Indian Ocean. Our primary objective was to identify contemporary high-use areas by the sharks to determine whether enhanced management or protection of the sharks is likely to be required.

\section{MATERIALS AND METHODS}

\section{Study area and boat surveys}

Eighty-one whale shark surveys, both in conjunction with tourism operators and on a private vessel, were conducted between September and December 2016 off the island of Nosy Be $\left(13.39^{\circ} \mathrm{S}, 48.20^{\circ} \mathrm{E}\right)$ in Antsiranana Province in northwestern Madagascar (Fig. 1). Search efforts were focused southwest of Nosy Be to about $10 \mathrm{~km}$ offshore, based on the experience of tourism professionals. Whale sharks were sighted when swimming close to the surface, often in association with mackerel tuna Euthynnus affinis and seabirds (particularly Laridae). Research was conducted with the approval of and in partnership with the Centre National de Recherches Océanographiques (CNRO) in Madagascar.

\section{Photo-identification}

Individual sharks were identified using standardized underwater photographs of each flank immediately posterior to the gills (Arzoumanian et al. 2005, Meekan et al. 2006). These images were uploaded to the online Wildbook for Whale Sharks (www.whaleshark.org) photo library, and a pattern-matching algorithm was used to identify individuals (Arzoumanian et al. 2005, Holmberg et al. 2008). Individual whale shark encounters were defined as a sighting of 


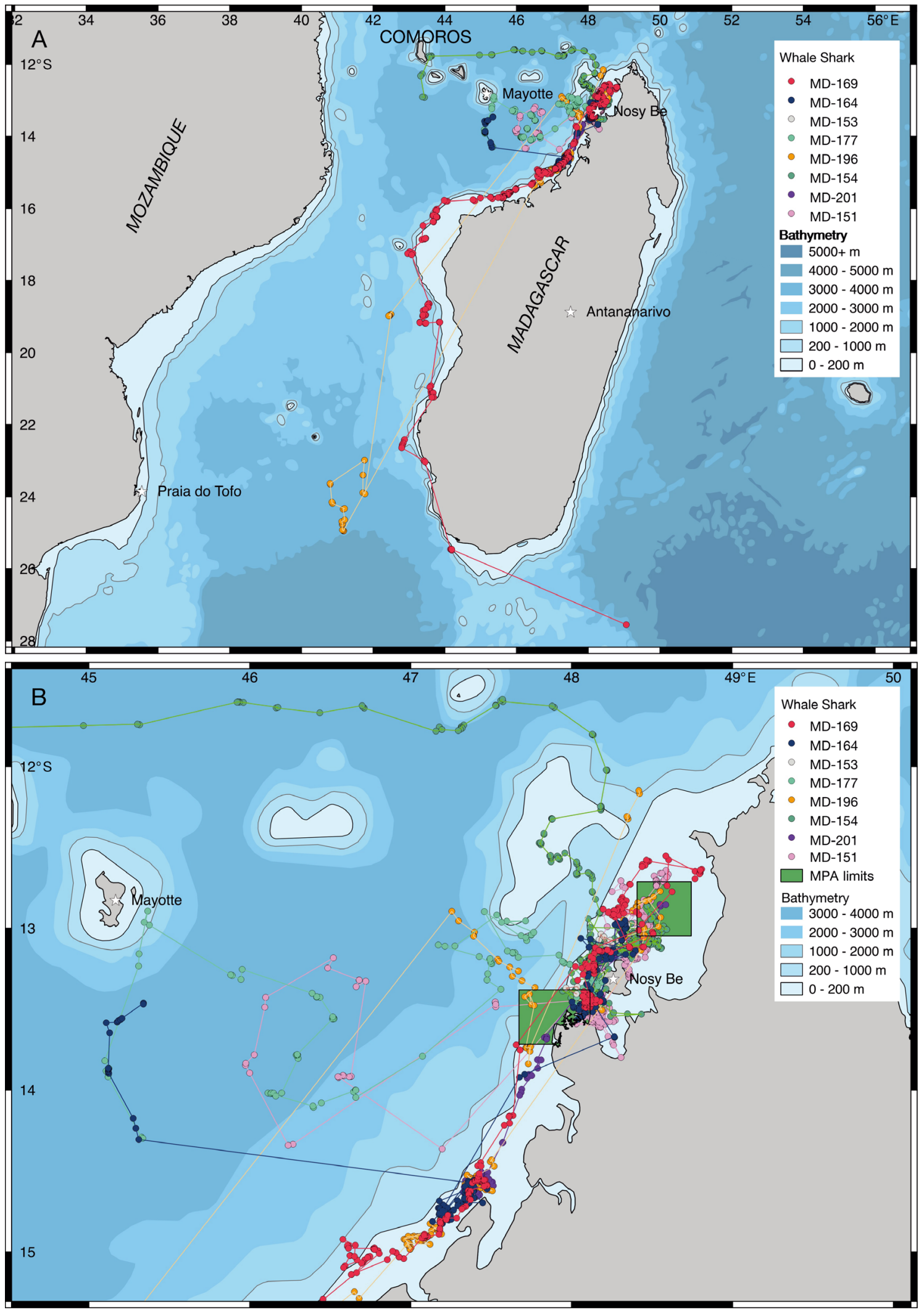

Fig. 1. Horizontal movements of whale sharks tagged with SPOT5 tags in Madagascar. (A) Eight individual shark tracks, all originating from Nosy $\mathrm{Be}_{\text {; }}$ (B) transmission sites from within the northwestern Madagascar area showing locations of marine protected areas (MPAs) 
an identified shark on a distinct day. TL was estimated visually to the nearest metre, and sex was assessed based on the presence (males) or absence of claspers (Norman \& Stevens 2007, Rohner et al. 2015a). Maturity status in whale sharks was established by visual observation of size for females, with the assumption that $<9 \mathrm{~m}$ sharks were immature (Ramírez-Macías et al. 2012, Acuña-Marrero et al. 2014), and calcification of claspers for males (Norman \& Stevens 2007, Rohner et al. 2015a).

\section{Satellite tagging}

Tagging activities were carried out on snorkel from a dedicated $4 \mathrm{~m}$ private vessel. Smart position or temperature transmitting tags (SPOT5, Wildlife Computers) were used to collect positional data on shark movements. SPOT5 tags are designed to transmit near real-time animal positions. When at the surface, they send short transmissions to the Argos satellite system. Consecutive transmissions, when received within a single satellite pass, are used to calculate the tag's location. We used SPOT5 tags over archival tag models because they provide a detailed location with a much smaller error than light level-derived locations, and the main aim of the study was to investigate the horizontal movements of whale sharks in detail. The SPOT5 tags were also set to collect and transmit temperature data, which can be useful both as a rough proxy for vertical movements and, as such, to confirm that the tag remains attached to the shark (Hearn et al. 2013) (see details of analyses in the next subsection). Tags were connected to a small titanium dart (Wildlife Computers) via a $\sim 150 \mathrm{~cm}$ tether of $240 \mathrm{~kg}$ Dyneema braided line. The dart was inserted into the skin using a pole spear so that the tag floated approximately above the first dorsal fin. Most sharks showed no obvious reaction to tagging, with the minority of sharks that increased their swimming speed immediately post tagging resuming their previous behavior in 1 to $2 \mathrm{~min}$.

\section{Track analysis}

Once detached, floating tags were identified by near-continuous transmissions to Argos in the first few hours of the day over several consecutive days, coupled with no significant vertical movement inferred from time-at-temperature (TAT) histograms (Hearn et al. 2013). We then applied the Douglas filter (Douglas et al. 2012) to remove unrealistic locations based on the error associated with the Argos location class (lc: 3, 2, 1, 0, A, B, Z in decreasing order of accuracy). We set the filter to include all locations with $\mathrm{lc} \geq 1$ and used the maximum redundant distance method set to $10 \mathrm{~km}$. The filter removed 127 locations, or $6.3 \%$ of the total 2029 locations, but kept some B and A locations that had a relatively large error radius but were deemed accurate by the filter. We also corrected the time stamp from tag-recorded UTC to local time during this step, meaning that the limit of 300 transmissions a day UTC was split between 2 days in local time. This meant that the number of transmissions received per day could be larger than expected, with transmissions in the late evening and early morning local time. We used the Douglas filter output for all subsequent analyses.

Tags did not transmit every day, and hence we report the overall tracking duration as well as transmitting days (Table 1). Horizontal track distance was calculated by summing the straight-line distance between consecutive locations and therefore represents the minimum possible distance the shark swam horizontally. Analyses were conducted in $\mathrm{R}$ version

Table 1. Satellite track details of whale sharks tagged in Madagascar, with the tag number, shark ID on www.whaleshark.org, sex, estimated total length (TL), deployment and last transmission dates, tracking duration, number of transmitting days, overall track distance, mean speed, and the number of positions per (transmitting) day (where values in parentheses indicate the range)

\begin{tabular}{|c|c|c|c|c|c|c|c|c|c|c|}
\hline Tag & $\begin{array}{l}\text { Shark } \\
\text { ID }\end{array}$ & Sex & $\begin{array}{l}\mathrm{TL} \\
(\mathrm{m})\end{array}$ & Deployment & $\begin{array}{c}\text { Last } \\
\text { location }\end{array}$ & $\begin{array}{c}\text { Tracking } \\
\text { duration (d) }\end{array}$ & $\begin{array}{c}\text { Transmitting } \\
\text { days }\end{array}$ & $\begin{array}{c}\text { Track } \\
\text { distance }(\mathrm{km})\end{array}$ & $\begin{array}{c}\text { Speed } \\
\left(\mathrm{km} \mathrm{d}^{-1}\right)\end{array}$ & $\begin{array}{l}\text { Positions } \\
\text { per day }\end{array}$ \\
\hline 142221 & MD-151 & M & 4 & 27-Oct-16 & 22-Mar-17 & 147 & 68 & 2295 & 15.6 & $5.7+2.85(1-12)$ \\
\hline 142222 & MD-201 & M & 4 & 31-Oct-16 & 05-Dec-16 & 36 & 35 & 765 & 21.3 & $5.4+2.28(1-9)$ \\
\hline 142223 & MD-154 & M & 5.5 & 26-Oct-16 & 22-Jan-17 & 89 & 85 & 2160 & 24.3 & $4.7+2.15(1-12)$ \\
\hline 142224 & MD-196 & $\mathrm{F}$ & 7 & 29-Oct-16 & 14-May-17 & 198 & 50 & 4275 & 21.6 & $4.2+2.23(1-11)$ \\
\hline 142226 & MD-177 & $\mathrm{F}$ & 5 & 26-Oct-16 & 27-Nov-16 & 33 & 33 & 1126 & 34.1 & $4.5+2.32(1-10)$ \\
\hline 142227 & MD-153 & M & 6.5 & 28-Oct-16 & 05-Nov-16 & 9 & 7 & 191 & 21.2 & $4.7+1.70(2-7)$ \\
\hline 142230 & MD-164 & M & 7 & 27-Oct-16 & 13-May-17 & 199 & 46 & 1439 & 7.2 & $4.3+2.38(1-9)$ \\
\hline 142234 & MD-169 & M & 5 & 28-Oct-16 & $17-A p r-17$ & 172 & 69 & 3414 & 19.8 & $4.9+2.29(1-13)$ \\
\hline
\end{tabular}


1.0.136 ( $\mathrm{R}$ Core Team 2017). We created a density raster using the kernel density estimation tool heatmap in QGIS version 2.18.14 (QGIS Development Team 2017) to visualize hotspots of whale shark activity. Data input included all locations retained following application of the Douglas filter, and we used a kernel bandwidth of $10 \mathrm{~km}$, a quartic kernel shape, a cell size of $0.5 \mathrm{~km}$ and a decay ratio of 0 . Values of 0 to $24.9 \%$ were removed from the output.

Tags recorded temperatures in 12 predefined bins: $<5^{\circ} \mathrm{C}$, 5 to $10^{\circ} \mathrm{C}$, then every $2.5^{\circ} \mathrm{C}$ to $32.5^{\circ} \mathrm{C}$, and $>32.5^{\circ} \mathrm{C}$. Temperatures were measured every $10 \mathrm{~s}$ and integrated over 3 separate time periods for each $24 \mathrm{~h}$ day (morning $=06: 00-12: 00 \mathrm{~h}$; afternoon $=$ 12:00-18:00 $h$; night $=18: 00-06: 00 h$ ) to calculate TAT histograms. There were large gaps in the TAT time series because tags only transmitted data on $45 \%$ of tracking days overall. We did not plot these gaps, meaning that the $x$-axes of TAT plots are chronological but not continuous. We extracted bathymetric data using the xtractomatic package in R (Mendelssohn 2015) for those records in the TAT time series that also had a simultaneous location transmitted. We divided depth data into (1) on the continental shelf $(<200 \mathrm{~m}$ deep) and (2) off the shelf $(>200 \mathrm{~m})$ for graphical output.

\section{RESULTS}

\section{Photo-identification}

Eighty-five individual whale sharks were recorded from 166 separate encounters between September and December 2016: 18 females (size range 5-7.5 m TL), 66 males (size range 3.5-8 $\mathrm{m} \mathrm{TL}$ ), and 1 shark of unknown sex. All were immature, based on a lack of clasper calcification in males and the estimated TL of females. None of these sharks had been previously identified in surrounding countries.

\section{Tag performance and horizontal movements}

Eight juvenile whale sharks, 6 males and 2 females ranging from 4 to $7 \mathrm{~m} \mathrm{TL}$, were tracked between October 2016 and May 2017 (Table 1). The SPOT5 tags stayed attached for 9 to $199 \mathrm{~d}$ (mean $\pm \mathrm{SD}=110$ $\pm 78.3 \mathrm{~d}$ ). Data were transmitted on 7 to $87 \mathrm{~d}$ (mean \pm $\mathrm{SD}=49 \pm 24.7 \mathrm{~d}$ ). The 4 tags that stayed on for $>100 \mathrm{~d}$ transmitted on $<50 \%$ of the days (range $=23-46 \%$ ), while the 4 tags with shorter retention times transmitted on most days (mean $\pm \mathrm{SD}=93 \pm 10.1 \%$, range
$=78-100 \%)$. Tags transmitted a mean of 4.8 locations per transmitting day. Straight-line horizontal track distances ranged from 191 to $4275 \mathrm{~km}$, with 6 of the 8 tracks longer than $1000 \mathrm{~km}$. Sharks travelled at a mean horizontal speed of $21 \mathrm{~km} \mathrm{~d}^{-1}$.

Tagged whale sharks spent substantial time near the tagging area around Nosy Be, but some broader movements to the west into the Mozambique Channel and to the south along the west coast of Madagascar were also recorded (Fig. 1A). Two whale sharks swam to the southern end of Madagascar, with MD196 moving offshore in the southern Mozambique Channel before returning to the Nosy Be area and MD-169 following the continental shelf break south before losing its tag southeast of Madagascar. One of these (MD-196) and 4 other sharks swam off the shelf into the northeastern Mozambique Channel, between Madagascar and Mayotte, and one (MD-154) continued to near the Comoros islands (Fig. 1B). Two sharks (MD-153 and MD-201) stayed on the shelf, albeit over relatively short tracking durations ( 9 and $36 \mathrm{~d}$, respectively). Kernel density estimates displayed 2 whale shark activity hotspots (Fig. 2) on the continental shelf, one close to the tagging locations near Nosy Be and a secondary hotspot $\sim 180 \mathrm{~km}$ to the southeast near Pointe d'Analalava.

Following the conclusion of the study, 3 sharks were resighted in the Nosy Be area after tag detachment: MD-201 was sighted on 3 November 2017, MD-151 was identified on multiple days in September and October 2017, and MD-177 was sighted on 23 July 2017.

\section{TAT}

There were 218 TAT records available for all tags combined. Sharks moved through the entire temperature range of temperature bins, $<5$ to $>32.5^{\circ} \mathrm{C}$. Based on the transmitted data, whale sharks spent most of their time in the $27.5-30^{\circ} \mathrm{C}(59.4 \%)$ and $25-27.5^{\circ} \mathrm{C}$ $(29.5 \%)$ bins (Fig. 3a). Tag-derived sea surface temperature values ranged from $27.3^{\circ} \mathrm{C}$ in October 2016 to a maximum of $29.8^{\circ} \mathrm{C}$ in February 2017, declining to a minimum of $25.3^{\circ} \mathrm{C}$ in April 2017 . Only $3.1 \%$ of time was spent in $<20^{\circ} \mathrm{C}$. There were some apparent diel differences observed among TAT data from the morning (06:00-12:00 h), afternoon (12:00-18:00 h) and night (18:00-06:00 h). Sharks spent $0.9 \%$ of the afternoon in cool water $<20^{\circ} \mathrm{C}$, increasing to $3.3 \%$ in the morning and $5.1 \%$ at night (Fig. 3).

Vertical movements, as inferred from the available TAT time series, varied among individuals. Broadly, 


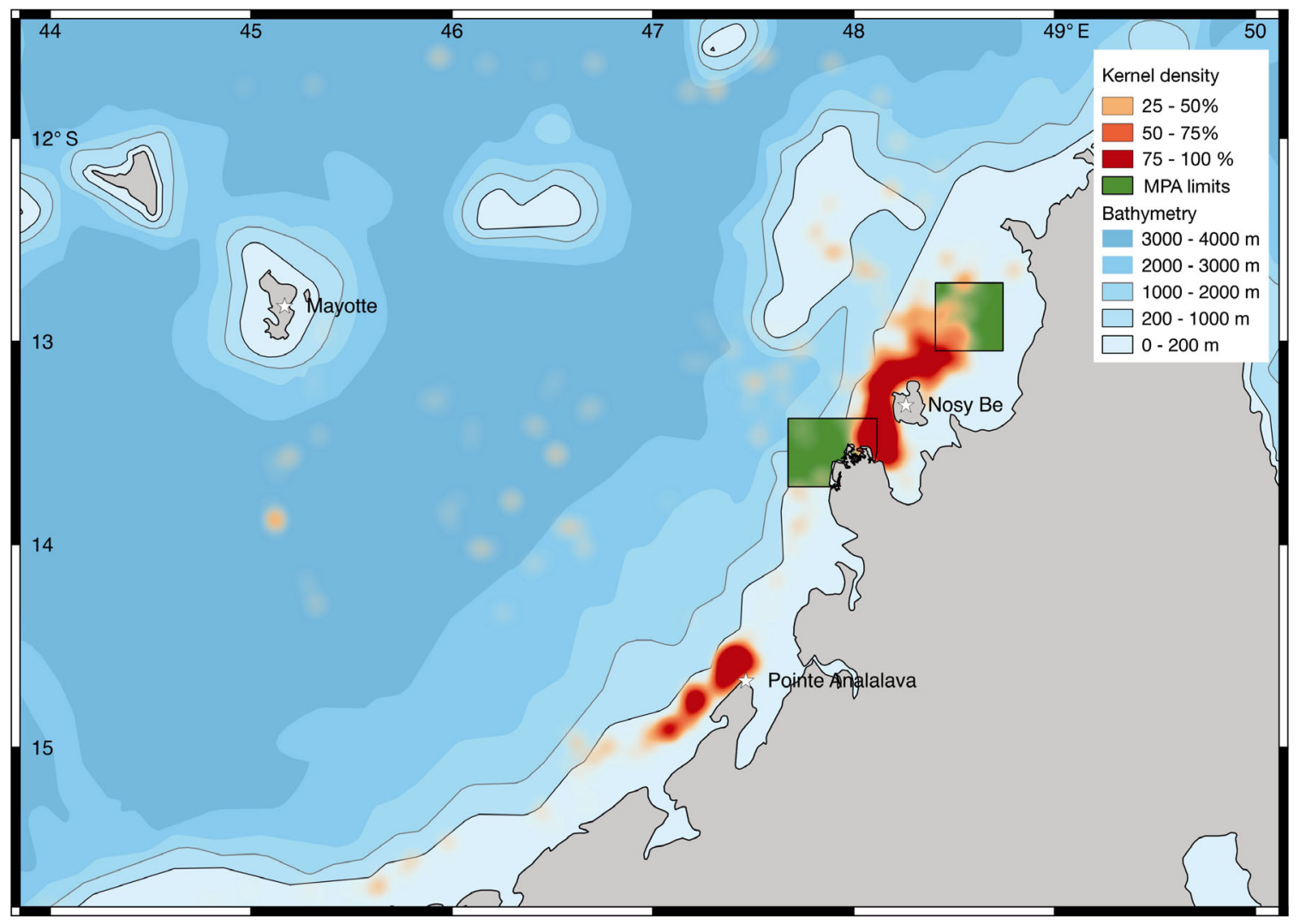

Fig. 2. Kernel density estimation of whale shark distribution based on transmissions of the satellite-tagged sharks (n = 8). MPA: marine protected area

sharks spent more time at cooler temperatures when they were off the shelf and during the night and morning. As an example, shark MD-177 (Fig. 4) spent the first $12 \mathrm{~d}$ of its track on the continental shelf, where it recorded no vertical excursions into deep (cool) water. This shark then moved off the shelf to the open ocean, over deep water. The recorded temperature range then increased, with the shark spending more time in cooler waters, especially at night and during the morning (Fig. 4).

\section{DISCUSSION}

The Nosy Be area appears to be a globally significant whale shark hotspot, with 85 individual sharks identified during the 3 mo whale shark season (as identified by local tourist operators) in 2016. By way of comparison, 33 individual whale sharks were identified in Mozambique and 70 in Tanzania during 2016 (C.A.R. \& S.J.P. unpubl. data). Two distinct hotspots of whale shark activity were identified in northwestern Madagascar, the first around the tag- ging site off Nosy Be and a second $180 \mathrm{~km}$ south, close to Pointe d'Analalava, identified by kernel density analysis of transmitted locations. Although the Nosy Be hotspot is near (relative to observed shark movement capability) previously identified whale shark feeding areas around Praia do Tofo in Mozambique (1760 km, Cliff et al. 2007, Pierce et al. 2010), Mahé in the Seychelles (1250 km, Rowat et al. 2009, 2011) and Mafia Island in Tanzania (1120 km, Rohner et al. 2015b), we found no evidence of movements to or from these known sites through our tracking or photo-identification datasets. However, the sharks were tracked moving close to the islands of Comoros and Mayotte (France) in the Mozambique Channel, showing that international movement does occur.

\section{Northwestern Madagascar, a significant whale shark hotspot}

Quantitative hotspot analysis determined that most satellite tag transmissions occurred off the island of Nosy Be, with a secondary hotspot used by 4 sharks 

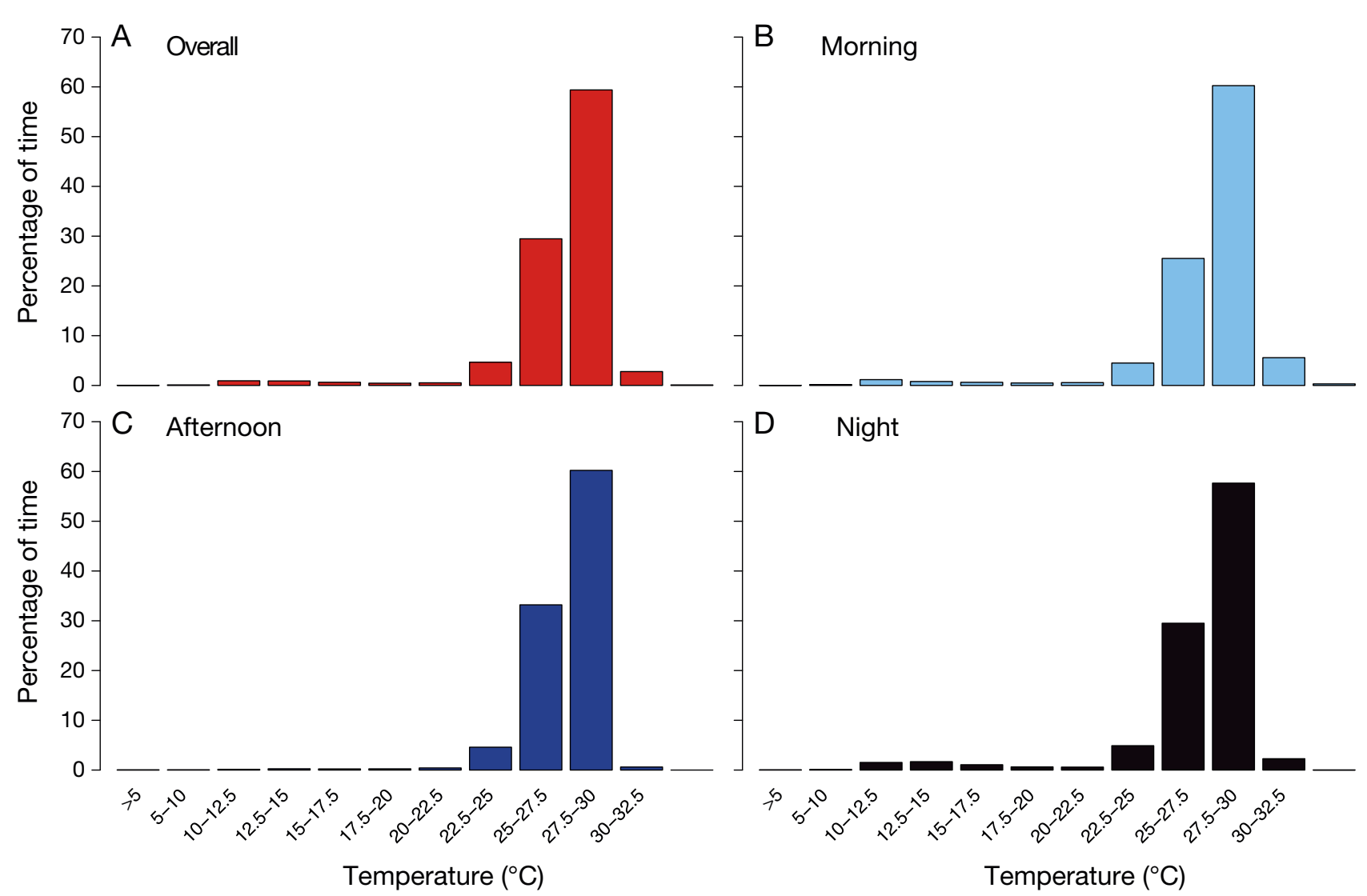

Fig. 3. Time-at-temperature for all tags combined, showing (A) the overall distribution and (B) the morning (06:00-12:00 h), (C) afternoon (12:00-18:00 h), and (D) night (18:00-06:00 h) separately

at Pointe d'Analalava, slightly to the south. These 2 areas were both identified as whale shark hotspots by Jonahson \& Harding (2007) through interview surveys of fishers and dive operators, suggesting that these areas are consistently used by whale sharks across years. There was temporal overlap in use of these 2 areas by the tagged sharks. Rowat \& Brooks (2012, p 1032) defined whale shark aggregations as 'sites with $>10$ individuals in an area $<1 \mathrm{~km}^{2}$.' While we did not observe tight groupings of multiple sharks in this study, the relatively high number of whale sharks documented in the Nosy Be area, and the inter-annual site fidelity demonstrated by some tagged sharks, indicates that this is an important seasonal habitat for juvenile sharks.

The biased population structure of whale sharks present, with the majority being juvenile male sharks, is common within their coastal feeding areas (Rohner et al. 2015a). While we inferred no specific behaviors from tracking data, Nosy Be is also likely to be a feeding area for these whale sharks. Most whale sharks sighted, including all tagged sharks, were associated with surface schools of mackerel tuna feeding on small pelagic fishes (Clupeidae), which were presumably also being targeted by the whale sharks. Omura's whales Balaenoptera omurai also feed in the same area on zooplankton, occasionally in association with whale sharks (Cerchio et al. 2015a). Giant manta rays Mobula birostris and devil rays $M$. mobular and $M$. thurstoni, which feed on zooplankton and small fishes (Rohner et al. 2017), also co-occur in this area (M. Jonahson \& S. Harding pers. obs.), indicating a high level of prey availability. No adult sharks were recorded during field surveys, so it is unlikely to be a reproductive site. The temperature range $\left(27.5-30^{\circ} \mathrm{C}\right)$ recorded for locations on the shelf was similar to surface water temperatures, indicating that little diving behavior took place, which is further supported by the high number of daily surface transmissions in this area.

\section{Broad-scale movements through the southwestern Indian Ocean}

The 5 sharks tracked into January 2017 all moved away from the Nosy Be area. January is typically the 

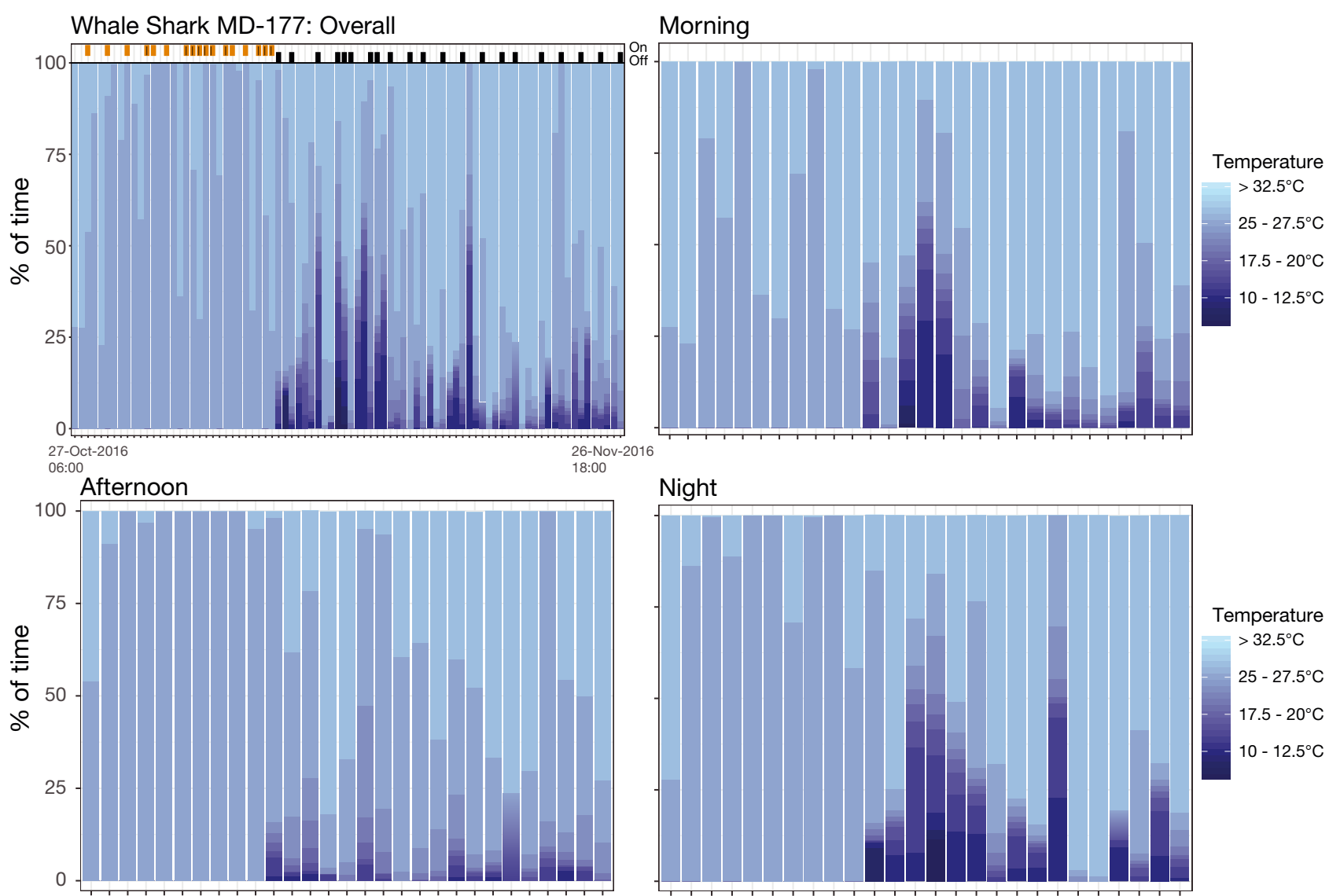

Fig. 4. Time-at-temperature data for whale shark MD-177, showing the percentage of time spent in each temperature bin overall and during the 3 temporal bins: morning (06:00-12:00 h), afternoon (12:00-18:00 h) and night (18:00-06:00 h). In the top left panel 'On' indicates that the shark was on the continental shelf in water $<200 \mathrm{~m}_{i}$ 'Off' indicates that it was off the shelf in deeper water. Note that the $x$-axis is chronological but not continuous due to gaps in data transmission

start of cyclone season in northwestern Madagascar (Brenier \& Vogel 2017) and, related to this, dedicated whale shark tourism ceases. Fewer transmissions from tags were received after this time, suggestive of diminished surface activity and more time spent on directed travel. Four of the 8 tagged sharks moved west of Nosy Be, towards the islands of Mayotte and the Comoros, a region with seasonally high densities of whale sharks (Sequeira et al. 2012). Two sharks, MD-169 and MD-196, travelled to the south of Madagascar, although MD-196 subsequently returned to Nosy Be (a $4275 \mathrm{~km}$ horizontal distance in total). Both sharks dived to cold temperatures of between 5.1 and $10^{\circ} \mathrm{C}$ while in oceanic waters. We have no contemporaneous data on vertical temperature profiles in this region, but an array of oceanographic sensors across the Mozambique Channel from 2003 to 2009 found that on average, the temperature was close to $10^{\circ} \mathrm{C}$ at $500 \mathrm{~m}, 6^{\circ} \mathrm{C}$ at $1000 \mathrm{~m}$ and $4^{\circ} \mathrm{C}$ at $1500 \mathrm{~m}$ (Ullgren et al. 2012). However, the passage of eddies southwards through the array resulted in up to $8^{\circ} \mathrm{C}$ changes in temperature at $110 \mathrm{~m}$ depth, so the relationship between depth and temperature is not strictly linear within this dynamic system (Ullgren et al. 2012). A whale shark tagged with a pop-up archival tag by Brunnschweiler et al. (2009) in the southern Mozambique Channel recorded temperatures of $9.2^{\circ} \mathrm{C}$ at $1092 \mathrm{~m}, 5.5^{\circ} \mathrm{C}$ at $1087 \mathrm{~m}$ and $4.2^{\circ} \mathrm{C}$ at $1264 \mathrm{~m}$.

MD-169 moved to the southeast of Madagascar, where an important upwelling system that can be highly productive in the late austral summer had been previously identified (Uz 2007, Huhn et al. 2012). A tagged whale shark from southern Mozambique also moved to this area in autumn 2006 (Brunnschweiler et al. 2009). It appears that the Indian Ocean tuna fishing fleet does not routinely use the waters off southern Madagascar, so no observer data on whale shark presence or absence have been documented (Sequeira et al. 2012). Therefore, while it is possible that this is an additional whale shark foraging area, we are not aware of additional data to support this hypothesis. 


\section{Management and conservation implications}

Northwestern Madagascar is a significant longterm hotspot for a number of threatened marine megafauna species, including whale sharks (Jonahson \& Harding 2007, this study), cetaceans (Cerchio et al. 2015a,b) and sea turtles (Bourjea et al. 2006). The area is also a global hotspot of coral biodiversity (Brenier \& Vogel 2017). The presence of whale sharks, a diversity of cetacean species and sea turtles in this region is already a major tourism attraction for Nosy $\mathrm{Be}$, presenting both a biological and economic rationale to manage the area for long-term sustainability. Local interest in the species is high, and most tourism operators have already implemented best-practice voluntary guidelines for whale shark interactions off Nosy Be.

It appears that whale sharks are at a low risk of fishing-related injury or mortality within the Ankivonjy and Ankarea MPAs, located to the southwest and northeast of Nosy Be, respectively, based on the gear restrictions in place (Brenier \& Vogel 2017). They are currently afforded no official protection outside these areas, and there is no legislation in place specifically pertaining to elasmobranchs in the country (Humber et al. 2015). The recent listing of the whale shark in CMS Appendix I (October 2017) does compel Madagascar to prohibit take of the species, with limited exceptions possible for traditional subsistence use (www.cms.int/en/node/3916). Dolphin bycatch in gillnets has been documented in the Nosy Be area, particularly from Nosy Faly to the east of Nosy Be (Cerchio et al. 2015b). Whale sharks have occasionally been caught or entangled in gillnets in Madagascar (Jonahson \& Harding 2007, Everett et al. 2015). Therefore, a restriction of gillnet use throughout the identified whale shark activity centres to minimize the risk of accidental bycatch or directed fishing is recommended. Management of tuna fisheries in the area may also require attention, given the strong association between whale sharks and mackerel tuna schools we observed.

Acknowledgements. Thanks to the staff of Les Baleines Rand'eau and other tourism operators for their cooperation and assistance with this study and to the Mada Megafauna team for practical and logistical support. We thank field assistants Fadia Al Abbar and Jens Paulsen for their work over the 2016 season as well as Boris Andrianantenaina, Mamy Rajaonarivelo and Gisèle Bakary from CNRO for their help with research permits. Salvatore Cerchio, Dení Ramírez-Macías, Clare Prebble and Alexandra Watts provided technical support, and Gonzalo Araujo and the LAMAVE team in the Philippines as well as Ralph Pannell from Aqua-Firma helped with logistical arrangements. This study was financially supported by donations to S.J.P. and C.A.R. from 2 private trusts, Aqua-Firma, the Shark Foundation and Waterlust. Field costs for S.D. were covered by the PADI Foundation, and camera equipment was donated by Idea Wild. This research used data and software tools provided by Wildbook for Whale Sharks, an online markrecapture database operated by the non-profit scientific organization Wild Me with support from public donations and the Qatar Whale Shark Research Project. We thank Professor Rory Wilson and 3 anonymous reviewers for their constructive comments which improved this work. Authorisation to deploy satellite tags on whale sharks was granted by CNRO in July 2016 under the number N ${ }^{\circ}$ 16-12-CNRO-N.

\section{LITERATURE CITED}

Acuña-Marrero D, Jiménez J, Smith F, Doherty PF Jr and others (2014) Whale shark (Rhincodon typus) seasonal presence, residence time and habitat use at Darwin Island, Galapagos Marine Reserve. PLOS ONE 9:e11 5946

Andrzejaczek S, Meeuwig J, Rowat D, Pierce S, Davies T, Fisher R, Meekan MG (2016) The ecological connectivity of whale shark aggregations in the Indian Ocean: a photo-identification approach. R Soc Open Sci 3:160455

Arzoumanian Z, Holmberg J, Norman B (2005) An astronomical pattern-matching algorithm for computer-aided identification of whale sharks Rhincodon typus. J Appl Ecol 42:999-1011

Bourjea J, Ciccione S, Ratsimbazafy R (2006) Marine turtles surveys in Nosy Iranja Kely, north-western Madagascar. West Indian Ocean J Mar Sci 5:209-212

Brenier A, Vogel A (2017) Integrating conservation and development in Madagascar's marine protected areas. FAO Fish Aquacult Tech Pap 603:85-98

Brooks K, Rowat D, Pierce SJ, Jouannet D, Vély M (2010) Seeing spots: photo-identification as a regional tool for whale shark identification. West Indian Ocean J Mar Sci 9:185-194

Brunnschweiler JM, Baensch H, Pierce SJ, Sims DW (2009) Deep-diving behaviour of a whale shark Rhincodon typus during long-distance movement in the western Indian Ocean. J Fish Biol 74:706-714

Castro ALF, Stewart BS, Wilson SG, Hueter RE and others (2007) Population genetic structure of Earth's largest fish, the whale shark (Rhincodon typus). Mol Ecol 16: 5183-5192

* Cerchio S, Andrianantenaina B, Lindsay A, Rekdahl M, Andrianarivelo N, Rasoloarijao T (2015a) Omura's whales (Balaenoptera omurai) off northwest Madagascar: ecology, behaviour and conservation needs. R Soc Open Sci 2:150301

Cerchio S, Andrianarivelo N, Andrianantenaina B (2015b) Ecology and conservation status of Indian Ocean humpback dolphins (Sousa plumbea) in Madagascar. Adv Mar Biol 72:163-199

Cliff G, Anderson-Reade MD, Aitken AO, Charter GE, Peddemors VM (2007) Aerial census of whale sharks (Rhincodon typus) on the northern KwaZulu-Natal coast, South Africa. Fish Res 84:41-46

* Douglas DC, Weinzierl R, Davidson SC, Kays R, Wikelski M, Bohrer G (2012) Moderating Argos location errors in animal tracking data. Methods Ecol Evol 3:999-1007 
Everett BI, Jiddawi N, Wambiji N, Boinali K, Andriamaharo T, Oodally Z, Chauca I (2015) WIOFish database: a catalogue of small scale fisheries of the western Indian Ocean: biennial report for 2014 and 2015. www.wiofish.org/portal/ wiofishdb/UserFiles/SysDocs/bb_content/10000/2/WIO Fish\%20Biennial\%20Report\%202015.pdf (accessed 8 May 2018)

Gifford A, Compagno LJV, Levine M, Antoniou A (2007) Satellite tracking of whale sharks using tethered tags. Fish Res 84:17-24

Hearn AR, Green JR, Espinoza E, Peñaherrera C, Acuña D, Klimley AP (2013) Simple criteria to determine detachment point of towed satellite tags provide first evidence of return migrations of whale sharks (Rhincodon typus) at the Galapagos Islands, Ecuador. Anim Biotelem 1:11

Holmberg J, Norman B, Arzoumanian Z (2008) Robust, comparable population metrics through collaborative photomonitoring of whale sharks Rhincodon typus. Ecol Appl 18:222-233

Huhn F, von Kameke A, Pérez-Muñuzuri V, Olascoaga MJ, Beron-Vera FJ (2012) The impact of advective transport by the South Indian Ocean Countercurrent on the Madagascar plankton bloom. Geophys Res Lett 39:L06602

*Humber F, Andriamahefazafy M, Godley BJ, Broderick AC (2015) Endangered, essential and exploited: how extant laws are not enough to protect marine megafauna in Madagascar. Mar Policy 60:70-83

Jonahson M, Harding S (2007) Occurrence of whale sharks (Rhincodon typus) in Madagascar. Fish Res 84:132-135

Kiszka J, van der Elst RP (2015) Elasmobranchs (sharks and rays): a review of status, distribution and interaction with fisheries in the southwest Indian Ocean. Oceanogr Res Inst (Spec Publ) 10:365-389

*Meekan MG, Bradshaw CJA, Press M, McLean C, Richards A, Quasnichka S, Taylor JG (2006) Population size and structure of whale sharks Rhincodon typus at Ningaloo Reef, Western Australia. Mar Ecol Prog Ser 319:275-285

Mendelssohn R (2015) xtractomatic: extracts environmental data from ERD's ERDDAP web service. https://github. com/rmendels/xtractomatic (accessed 8 May 2018)

Norman B, Stevens J (2007) Size and maturity status of the whale shark (Rhincodon typus) at Ningaloo Reef in Western Australia. Fish Res 84:81-86

Norman BM, Holmberg JA, Arzoumanian Z, Reynolds S and others (2017) Undersea constellations: the global biology of an endangered marine megavertebrate further informed through citizen science. Bioscience 67 : 1029-1043

Pierce SJ, Norman B (2016) Rhincodon typus. The IUCN Red List of Threatened Species 2016:e.T19488A2365291. http://dx.doi.org/10.2305/IUCN.UK.2016-1RLTS. T19488A2365291.en (accessed 8 May 2018)

Pierce SJ, Méndez-Jiménez A, Collins K, Rosero-Caicedo M, Monadjem A (2010) Developing a code of conduct for whale shark interactions in Mozambique. Aquat Conserv 20:782-788

QGIS Development Team (2017) QGIS geographic information system. Open Source Geospatial Foundation. https:// www.qgis.org/en/site/ (accessed 8 May 2018)

R Core Team (2017) R: a language and environment for statistical computing. R Foundation for Statistical Computing, Vienna. www.R-project.org/

Ramírez-Macías D, Vázquez-Haikin A, Vázquez-Juárez R (2012) Whale shark Rhincodon typus populations along the west coast of the Gulf of California and implications for management. Endang Species Res 18:115-128

* Ramírez-Macías D, Queiroz N, Pierce SJ, Humphries NE, Sims DW, Brunnschweiler JM (2017) Oceanic adults, coastal juveniles: tracking the habitat use of whale sharks off the Pacific coast of Mexico. PeerJ 5:e3271

* Robinson DP, Jaidah MY, Bach S, Lee K and others (2016) Population structure, abundance and movement of whale sharks in the Arabian Gulf and the Gulf of Oman. PLOS ONE 11:e0158593

Rohner CA, Pierce SJ, Marshall AD, Weeks SJ, Bennett MB, Richardson AJ (2013) Trends in sightings and environmental influences on a coastal aggregation of manta rays and whale sharks. Mar Ecol Prog Ser 482:153-168

* Rohner CA, Richardson AJ, Prebble CEM, Marshall AD and others (2015a) Laser photogrammetry improves size and demographic estimates for whale sharks. PeerJ 3:e886

Kohner CA, Armstrong AJ, Pierce SJ, Prebble CEM and others (2015b) Whale sharks target dense patches of sergestid shrimp off Tanzania. J Plankton Res 37:352-362

Rohner CA, Burgess KB, Rambahiniarison JM, Stewart JD, Ponzo A, Richardson AJ (2017) Mobulid rays feed on euphausiids in the Bohol Sea. R Soc Open Sci 4:161060

* Rohner CA, Richardson AJ, Jaine FRA, Bennett MB and others (2018) Satellite tagging highlights the importance of productive Mozambican coastal waters to the ecology and conservation of whale sharks. PeerJ 6:e4161

Rowat D, Brooks KS (2012) A review of the biology, fisheries and conservation of the whale shark Rhincodon typus. J Fish Biol 80:1019-1056

* Rowat D, Meekan MG, Engelhardt U, Pardigon B, Vely M (2007) Aggregations of juvenile whale sharks (Rhincodon typus) in the Gulf of Tadjoura, Djibouti. Environ Biol Fishes 80:465-472

* Rowat D, Speed CW, Meekan MG, Gore MA, Bradshaw CJA (2009) Population abundance and apparent survival of the vulnerable whale shark Rhincodon typus in the Seychelles aggregation. Oryx 43:591-598

Rowat D, Brooks K, March A, McCarten C and others (2011) Long-term membership of whale sharks (Rhincodon typus) in coastal aggregations in Seychelles and Djibouti. Mar Freshw Res 62:621-627

* Ryan JP, Green JR, Espinoza E, Hearn AR (2017) Association of whale sharks (Rhincodon typus) with thermo-biological frontal systems of the eastern tropical Pacific. PLOS ONE 12:e0182599

* Schmidt JV, Schmidt CL, Ozer F, Ernst RE, Feldheim KA, Ashley MV, Levine M (2009) Low genetic differentiation across three major ocean populations of the whale shark, Rhincodon typus. PLOS ONE 4:e4988

* Sequeira AMM, Mellin C, Rowat D, Meekan MG, Bradshaw CJA (2012) Ocean-scale prediction of whale shark distribution. Divers Distrib 18:504-518

* Ullgren JE, van Aken HM, Ridderinkhof H, de Ruijter WPM (2012) The hydrography of the Mozambique Channel from six years of continuous temperature, salinity, and velocity observations. Deep Sea Res I 69:36-50

* Uz BM (2007) What causes the sporadic phytoplankton bloom southeast of Madagascar? J Geophys Res 112: C09010

*Vignaud TM, Maynard JA, Leblois R, Meekan MG and others (2014) Genetic structure of populations of whale sharks among ocean basins and evidence for their historic rise and recent decline. Mol Ecol 23:2590-2601 